\title{
Silver ion doped hydroxyapatite-coated titanium pins prevent bacterial colonization
}

\author{
Adnan Sevencan, $\mathrm{MD}^{1}{ }^{10}$, Elif Kartal Doyuk, $\mathrm{MD}^{2}{ }^{\circledR}$, Nusret Köse, $\mathrm{MD}^{1}$ (D) \\ 'Department of Orthopedics and Traumatology, Osmangazi University, Medical Faculty, Eskişehir, Turkey \\ ${ }^{2}$ Department of Infectious Diseases and Clinical Microbiology, Osmangazi University, Medical Faculty, Eskişehir, Turkey
}

Orthopedic implants are used in many patients. However, infection associated with medical implants remains one of the most important complications in modern trauma and orthopedic surgery. In addition to the economic burden, it may cause implant failure and multiple operations. ${ }^{[1]}$ The systemic treatment of infected implant with antibiotics is often poor, as the access of antibiotics to the infection site is inadequate. Adhesion of bacteria to the implant surface and biofilm formation are very critical stages in the progression of the infection. Bacteria colonize metal implants and create biofilms which suppress the penetration of immune defense factors and antibiotics to the underlying infection. ${ }^{[2]}$ Given the close relationship between infection and the implant surface, proper handling of the implant surface can help reduce the risk of infection. ${ }^{[3]}$ To improve the biocompatibility of metal implants, hydroxyapatite (HA) coatings are widely used. ${ }^{[4-6]}$ Ideally, the next step is to add antimicrobials to this coating.

Received: October 02, 2020

Accepted: December 08, 2020

Published online: December 21, 2020

Correspondence: Adnan Sevencan, MD. Osmangazi Üniversitesi Tıp Fakültesi Ortopedi ve Travmatoloji Anabilim Dalı, 26040 Meşelik, Eskişehir, Türkiye

E-mail: adnansevencan@hotmail.com

Doi: 10.5606/ehc.2021.79357

Citation: Sevencan A, Kartal Doyuk E, Köse N. Silver Ion doped hydroxyapatite-coated titanium pins prevent bacterial colonization. Jt Dis Relat Surg 2021;32(1):35-41.

(O2021 All right reserved by the Turkish Joint Diseases Foundation

This is an open access article under the terms of the Creative Commons Attribution-NonCommercial License, which permits use, distribution and reproduction in any medium, provided the original work is properly cited and is not used for commercial purposes (http://creativecommons.org/licenses/by-nc/4.0/).

\section{ABSTRACT}

Objectives: This study aims to evaluate the effectiveness of silver ion doped calcium phosphate-based ceramic nano powder-coated titanium pins in preventing bacterial colonization.

Materials and methods: A total of 66 titanium pins were divided into three groups of 22 implants. The first group was coated with silver ion doped calcium phosphate-based ceramic powder by using electrospray method. The second group was coated with pure hydroxyapatite (HA), and the remaining pins were used without any coating. The remaining 22 pins were used without any coating. Staphylococcus epidermidis clinical isolate was used for the study. Each pin was placed in $1 \times 10^{4} \mathrm{CFU} / \mathrm{mL}$ bacterial suspension containing tube and at $24 \mathrm{~h}$ quantitative culture of bacteria on the broth and on the pins were performed. Free silver ions were determined by atomic absorption method. The antibacterial culture tests were repeated on Day 2 and Weeks 2, 4, 6, and 8.

Results: Bacterial growth was statistically higher in broth containing uncoated pins, compared to broth media containing silver ion doped HA-coated, and pure HA-coated pins at $24 \mathrm{~h}$ $(p=0.036$ and $p=0.009$, respectively). The release of bacteria from silver doped HA-coated pins was statistically less, compared to pure HA-coated pins and uncoated pins $(\mathrm{p}=0.039$ and $\mathrm{p}=0.002$, respectively). No significant differences were observed between the HA-coated and uncoated pin groups. Minimum inhibitory concentration levels for silver ion doped powder was $8 \mu \mathrm{g} / \mathrm{mL}$ for coagulase-negative Staphylococcus. No free silver ions were detected in the broth media.

Conclusion: Silver ion doped nano size calcium phosphate-based powder-coated titanium pins reduced the bacterial colonization significantly. Using silver ion doped materials in the body can be a good option to prevent from implant related infections.

Keywords: Bacterial colonization, coated pin, infection, silver ion.

Various local delivery systems have been developed to prevent bacterial adhesion to the implant for antimicrobial prophylaxis, such as antimicrobial irrigation of the surgical site, dipping the implant in an antimicrobial solution, application of an antibacterial added polymer coating; however, these strategies are often applied in a non-standardized fashion and without clear 
evidence of clinical efficacy. ${ }^{[7]}$ Antibiotic resistance is an important issue in orthopedic implant infections. ${ }^{[8]}$ Implant-infecting Staphylococcus aureus (S. aureus) strains have high rates of antibiotic resistance, and there is an alarming increase of antibiotic resistance in other species, such as Staphylococcus epidermidis (S. epidermidis).. ${ }^{[9]}$ The increase in antibiotic-resistant pathogens, with the higher prevalence of infection leads to consideration of a material-based view of antimicrobials for implant-related infection. Silver is a good option for a metal-based therapeutic. Silver ions are well known to exhibit antimicrobial activity and have been incorporated into the surfaces of a variety of medical devices..$^{[10-14]}$

As the colonization of the bacteria (adherence and initial multiplication) is the first stage of implant related-infection, prevention of bacterial attachment to the implant by surface treatment is critical. In this experimental study, we aimed to evaluate the effectiveness of silver ion doped calcium phosphatebased ceramic nano powder-coated titanium pins in preventing bacterial colonization and to compare quantitative culture of bacteria on the broth and on the pins (coated and uncoated). Also, the minimum inhibitory concentration (MIC) value of the silver ion doped HA coating was determined.

\section{MATERIALS AND METHODS}

This experimental study was designed as a nonanimal and non-human, pure in vitro study and no ethic approval required. The study was conducted in accordance with the principles of the Declaration of Helsinki.

Sixty-six titanium pins with a length of $2.5 \mathrm{~cm}$ and a diameter of $0.2 \mathrm{~cm}$ were divided into three groups of 22 implants. The first group of titanium pins was coated with silver ion doped nano size HA powder using electrospray method. Radiofrequency (RF) was used to sinter the coated samples. The second group of pins was coated with pure HA with the same process. After sintering process, surface morphologies of pins were observed with scanning electron microscope (SEM, Zeiss Supra VP50). The remaining 22 pins were used without any coating. In each group, eight implant samples were sonicated to lyse bacteria and used for bacterial count. Since the choice of sterilization methods may cause changes in the chemical structure of the coatings and their bioactivity behavior, ${ }^{[15]}$ coated titanium pins were sterilized with ethylene oxide. Pressurized steam was used for the sterilization of uncoated pins.
In the study S. epidermidis clinical isolate, which is the major cause of foreign body (orthopedic implants) infections and which also causes the formation of slime (biofilm) virulence factor, was used. A total of $1 \times 10^{4} \mathrm{CFU} / \mathrm{mL}$ suspension of the clinical isolate in tryptic soy broth was prepared. ${ }^{[16]}$ After $1 \mathrm{~mL}$ of the bacteria suspension was transferred into glass tubes $(0.4 \mathrm{~cm}$ in diameter), each pin was placed in a tube in aseptic conditions. The tubes were sealed with parafilm and incubated at $35^{\circ} \mathrm{C} / 80 \mathrm{rpm}$ for $24 \mathrm{~h}$ in a shaking incubator to allow the bacteria adhere to the pins. Following $24 \mathrm{~h}$ incubation, quantitative culture and determination of silver ion by atomic absorption were performed on the broth containing three different pin groups. Also, quantitative culture of bacteria on the pins taken out glass tubes in aseptic conditions was performed in addition to microscopic examination. The possible antibacterial efficacy of implant coatings was investigated for eight weeks (Day 2, Weeks 2, 4, 6, and 8). Accordingly, the implants placed in shaking incubator at $35^{\circ} \mathrm{C} / 80 \mathrm{rpm}$ in glass tubes were rinsed with distilled water in aseptic conditions once a week.

Each broth sample was diluted in series up to a million times (from 10-1 to 10-6 times) using sterile broth. Of each dilution, 5\% was, then, inoculated onto sheep blood agar. Following $24 \mathrm{~h}$ incubation in aerobic media at $35^{\circ} \mathrm{C}$, the number of bacteria in the original broth culture was calculated by counting the colonies. S. epidermidis was identified using conventional methods and automated identification system (Phoneix, BD, USA). Titanium pins placed in tubes each containing $1 \mathrm{~mL}$ of ringer's lactate

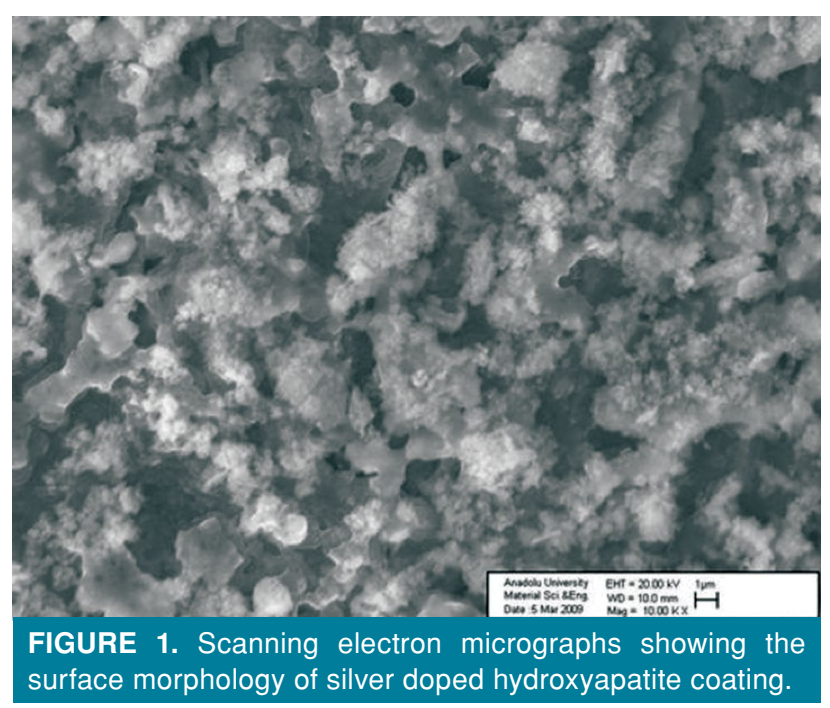




\begin{tabular}{|c|c|c|c|c|c|c|}
\hline \multicolumn{7}{|c|}{$\begin{array}{l}\text { TABLE I } \\
\text { Bacterial counts from the quantitative }\end{array}$} \\
\hline & Day 1 & Day 2 & Day 15 & Day 30 & Day 45 & Day 60 \\
\hline Silver 1 & 88.900 & & & & & \\
\hline Silver 2 & 13.100 & 100 & & & & \\
\hline Silver 3 & 0 & 100 & 18 & & & \\
\hline Silver 4 & 7.600 & 400 & 23 & 10 & 7 & \\
\hline Silver 5 & 0 & 3.500 & 18 & 7 & 6 & 4 \\
\hline Silver 6 & 73.600 & 0 & 22 & 6 & 11 & 3 \\
\hline Silver 7 & 39.700 & 600 & 13 & 12 & 6 & 7 \\
\hline Silver 8 & 81.600 & 1.400 & 13 & 29 & 2 & 2 \\
\hline Silver 9 & 25.100 & 1.000 & 22 & 14 & 0 & 4 \\
\hline Silver 10 & 47.300 & 100 & 14 & 8 & 3 & 6 \\
\hline Silver 11 & 56.000 & 1.000 & 12 & 2 & 1 & 3 \\
\hline Silver 12 & 112.500 & 0 & 13 & 10 & 4 & 2 \\
\hline Silver 13 & 22.900 & 2.200 & 18 & 12 & 1 & 5 \\
\hline Silver 14 & 107.300 & 3.500 & 14 & 16 & 4 & 0 \\
\hline HA1 & 56.000 & & & & & \\
\hline $\mathrm{HA} 2$ & 62.400 & 400 & & & & \\
\hline HA3 & 32.100 & 300 & 20 & & & \\
\hline HA4 & 126.400 & 1.500 & 9 & 7 & 2 & \\
\hline HA5 & 80.900 & 700 & 18 & 7 & 0 & 3 \\
\hline HA6 & 26.400 & 600 & 31 & 4 & 0 & 11 \\
\hline $\mathrm{HA} 7$ & 150.400 & 200 & 8 & 122 & 0 & 8 \\
\hline HA8 & 66.500 & 0 & 18 & 0 & 2 & 26 \\
\hline HA9 & 116.800 & 5.800 & 19 & 0 & 5 & 3 \\
\hline HA10 & 18.200 & 8.000 & 8 & 9 & 3 & 8 \\
\hline HA11 & 72.800 & 3.200 & 6 & 14 & 4 & 3 \\
\hline HA12 & 27.600 & 600 & 25 & 11 & 1 & 2 \\
\hline HA13 & 10.500 & 11.000 & 9 & 9 & 2 & 0 \\
\hline HA14 & 96.000 & 1.200 & 18 & 7 & 6 & 1 \\
\hline $\mathrm{T} 1$ & 22.900 & & & & & \\
\hline T2 & 9.500 & 6.200 & & & & \\
\hline Т3 & 25.800 & 700 & 15 & & & \\
\hline T4 & 12.500 & 14.000 & 4 & 10 & 2 & \\
\hline T5 & 6.000 & 0 & 23 & 9 & 0 & 0 \\
\hline T6 & 24.000 & 1.500 & 11 & 3 & 5 & 2 \\
\hline T7 & 12.500 & 5.700 & 10 & 6 & 11 & 1 \\
\hline T8 & 4.000 & 3.400 & 4 & 12 & 1 & 39 \\
\hline Т9 & 13.500 & 400 & 7 & 11 & 5 & 2 \\
\hline $\mathrm{T} 10$ & 64.000 & 3.200 & 22 & 14 & 2 & 3 \\
\hline T11 & 19.500 & 4.800 & 10 & 9 & 2 & 3 \\
\hline T12 & 10.000 & 600 & 23 & 3 & 3 & 6 \\
\hline T13 & 6.500 & 700 & 14 & 8 & 5 & 1 \\
\hline T14 & 26.000 & 19.300 & 12 & 9 & 4 & 2 \\
\hline
\end{tabular}

were sonicated for $60 \mathrm{sec}$ to allow for the lysis of the bacteria (Sonics Vibra-Cell VCX 750 ultrasonic homogeniser amplitude 20\%, 3-4 Watts, 200-230 Joules, 20 kHertz.).
The liquid from the tubes containing titanium pins were diluted in series and subjected to quantitative culture. Following incubation, bacterial count was performed as above. 


\begin{tabular}{|c|c|c|c|c|c|c|c|c|c|}
\hline \multicolumn{10}{|c|}{ TABLE II } \\
\hline & 1 & 2 & 3 & 4 & 5 & 6 & 7 & 8 & Mean \\
\hline Silver & 3.104 & 2.402 & 1.864 & 3.696 & 272 & 3.544 & 280 & 440 & 1.950 \\
\hline $\mathrm{HA}$ & 3.360 & 2.272 & 8.192 & 4.640 & 7.936 & 3.552 & 9.571 & 12.740 & 6.532 \\
\hline Uncoated & 17.920 & 7.040 & 2.848 & 4.132 & 9.540 & 8.950 & 8.861 & 10.128 & 8.677 \\
\hline
\end{tabular}

The MIC value of silver ion used for coating the implants was determined by agar dilution method according to the Clinical Laboratory Standards Institute (CLSI) guidelines. For agar dilution test, a series of two-fold agar dilutions ( 0.03 to $32 \mu \mathrm{g} / \mathrm{mL}$ ) of silver ion were prepared. As the quality control strains, S. aureus ATCC 29213 and Escherichia coli (E. coli) ATCC 25922 were used.

Following $24 \mathrm{~h}$ incubation, the presence of silver ion was investigated using atomic absorption method.

\section{Statistical analysis}

Statistical analysis was performed using the IBM SPSS version 22.0 software (IBM Corp., Armong, NY, USA). Due to the high number of data in groups, a normal distribution test was performed. One-way analysis of variance (ANOVA) was performed to compare the groups. Multiple comparisons (Tukey's honestly significant difference test) were done to identify differences among the groups. A $p$ value of $<0.05$ was considered statistically significant.

\section{RESULTS}

Surface morphologies of electrospray-coated and sintered silver ion doped calcium phosphate-based ceramic nano-powder coatings are shown in Figure 1. The SEM examinations of the pins showed that the coatings were homogenous with a uniform particle size.

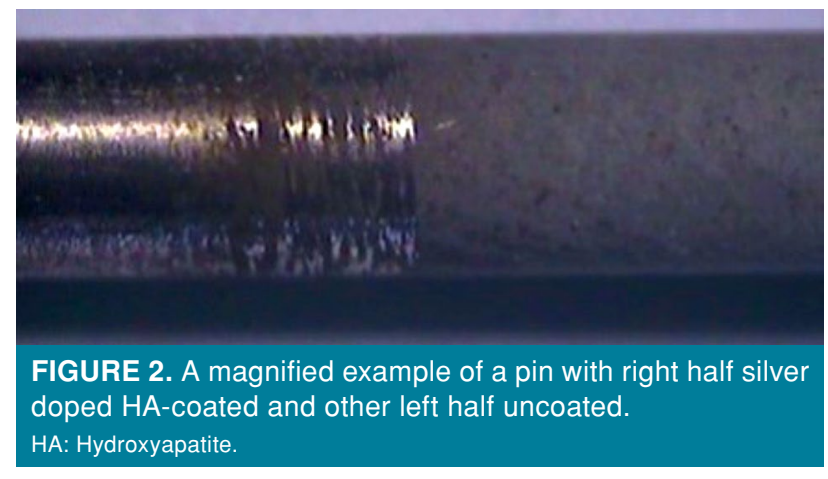

The results of quantitative cultures from broth media are presented in Table I. Normal distribution of data was shown by logarithmic transformation. The difference among the groups was significant only for measurements at $24 \mathrm{~h}$ in the analysis results $(p=0.008)$. No significant differences among the groups were detected at the other time points. In the ANOVA performed to identify the difference among the groups at $24 \mathrm{~h}$, the bacterial growth was statistically higher in broth containing uncoated pins, compared to broth media containing silver ion doped HA-coated and pure HA-coated titanium pins $(\mathrm{p}=0.036$ and $\mathrm{p}=0.009$, respectively).

Bacterial counts obtained from quantitative culture of bacteria lysed from the sonicated titanium implants are presented in Table II. Figure 2 shows an example of silver doped HA-coated and uncoated pins. The release of bacteria from silver ion doped HA-coated pins was statistically less, compared to pure HA-coated pins and uncoated pins ( $p=0.039$ and $p=0.002$, respectively) (Figure 3). No significant differences were observed between the pure HA-coated pin and uncoated titanium pin groups.

The MIC levels for silver ion doped nano size HA powder was $8 \mu \mathrm{g} / \mathrm{mL}$ for coagulase-negative staphylococcus and $8 \mu \mathrm{g} / \mathrm{mL}$ and $16 \mu \mathrm{g} / \mathrm{mL}$, respectively for the comparison of E. coli and S. aureus.

No free silver ions were detected in broth media using atomic absorption method which has a detection threshold as low as $0.02 \mathrm{mg} / \mathrm{L}$.

\section{DISCUSSION}

The present study proved that silver ion doped HA coating of titanium pins grossly inhibited bacterial colonization in the broth media and on the pins while comparing only HA coating or pure titanium pins. No free silver ions presentation in broth media containing silver-coated pins by atomic absorption method also showed the stabilization of this coating compound by electrospray method. 

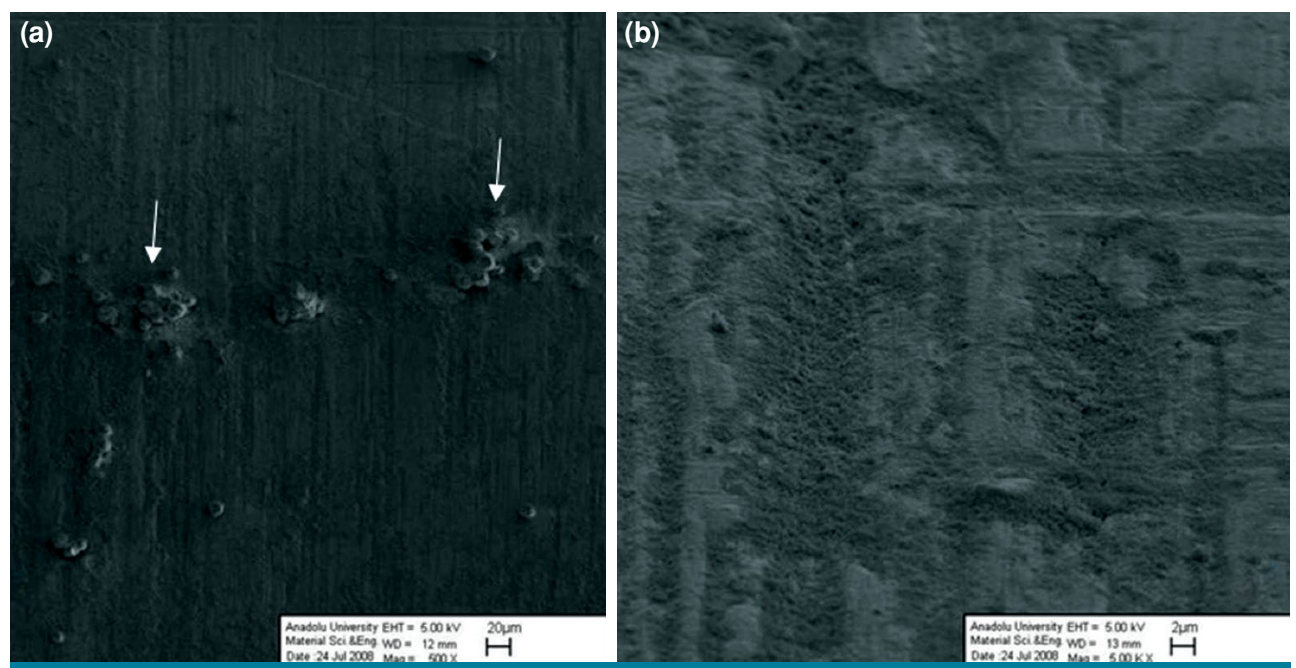

FIGURE 3. (a) Representative photos of Staphylococcus epidermidis plaque (arrows) on HA-coated pin (L side). (b) No plaques on silver doped HA-coated pin (R side).

HA: Hydroxyapatite.

Advances in orthopedic surgery have increased dependence on various medical devices and the number of patients in need of orthopedic implants has been growing rapidly. ${ }^{[17]}$ Titanium alloys have been widely used as orthopedic implant materials due to their good mechanical properties, chemical stability, and biocompatibility..$^{[18]}$ Long-term survival and favorable outcomes of orthopedic implant use are mainly determined by bone-implant osteointegration and absence of infection neighboring the implants. To improve the biocompatibility of titanium-based implants, various physical and chemical treatments have been used to modify the structure, composition, and chemistry of the titanium surfaces. Among the various techniques, HA coatings are widely used. ${ }^{[4-6]}$ Despite the great progress that has been achieved in orthopedic surgery, implant-related infection of bone and soft tissues remains as a serious problem. Although there is an interaction of various factors such as bacterial load, microorganism type, patient's immune status, surgical procedure and technique, implant type, and antibacterial prophylaxis in the emergence of implant-related infections, the most critical event is the onset of bacterial adhesion to an implant and the formation of biofilms which effectively protect microorganisms from the immune system and systemic antibiotics. ${ }^{[3]}$

The fight for implant-related infection continues, with emerging technologies targeting biofilm formation and methods to prevent adhesion and proliferation of micro-organisms to the metallic surfaces. ${ }^{[3,19]}$ Local antibacterial implant protection can be achieved in different ways. Romanò ${ }^{[20]}$ classified antibacterial coatings in three groups as passive surface modification, active surface modification, and perioperative antibacterial local carriers or coatings.

In the study, S. epidermidis was used as the infectious organism, as delayed infections caused by S. epidermidis are more dangerous and more difficult to treat than early infections caused by $S$. aureus. ${ }^{[21]}$ The most important findings of the study are that the bacterial growth was statistically higher in the broth containing uncoated pins, compared to the broth media containing silver ion doped HA-coated and pure HA-coated pins. No free silver ions were present in broth media containing silver-coated pins by atomic absorption method.

Bacterial counts obtained from quantitative culture of bacteria lysed from the sonicated implants showed that the release of bacteria from silver group was statistically less, compared to pure HA-coated pins and uncoated pins. No significant differences were detected between pure HA-coated and uncoated pins groups. Therefore, it can be speculated that the effect obtained depends on the silver ions in the structure and the novel coating with silver ions doped HA has antibacterial properties. It seems to be effective in reducing bacterial colonization.

In their study, Wiglusz et al. ${ }^{[22]}$ showed that the HA impregnated with the silver ions had a slightly better antimicrobial activity than HA with metallic silver. The authors reported that the 
minimal bactericidal concentration of $\mathrm{Ag}$ against Gram-positive bacteria was (S. aureus, $3.7 \mu \mathrm{g} / \mathrm{mL}$ ), indicating a lower concentration than our results. The MIC levels detected in our study for silver ion doped nano HA powder was $8 \mu \mathrm{g} / \mathrm{mL}$ for CNS and $8 \mu \mathrm{g} / \mathrm{mL}$ and $16 \mu \mathrm{g} / \mathrm{mL}$, respectively for the comparison of E. coli and S. aureus. No free silver ions were detected in broth media using atomic absorption method which has a detection threshold as low as $0.02 \mathrm{mg} / \mathrm{L}$.

There are two main types of coatings for effective antibacterial surface treatment as degradable and non-degradable with either "contact killing" or drug-eluting properties. Successful prophylaxis best achieved by local delivery devices, either made of degradable or non-degradable materials. ${ }^{[19]}$ Local delivery of high doses of antibiotics has disadvantages such as burst release than subtherapeutic dose of antibiotics. ${ }^{[19,22]}$ Also, the increase in antibioticresistant pathogens leads to consideration of a material-based view of antimicrobials for infection. ${ }^{[8,9,23]}$ Silver is a good option for a metalbased therapeutic. As an ionic form, it exhibits cytocompatibility, efficacy against planktonic and sessile bacteria, and bactericidal activity against many strains. ${ }^{[23]}$ The clinical incidence of silverresistant bacteria remains low, as silver, unlike common antibiotics, activates multiple mechanisms and hits different targets within the bacterial cells. ${ }^{[24,25]}$ In animal studies, silver-coated prosthesis and implant applications have been shown to reduce the likelihood of infection. There has been a concern, however, about the toxicity of silver ions. The research efforts have focused on the development of silver coating technologies which reduce or even eliminate toxicity, while maintaining antibacterial effects. ${ }^{[19]}$

Darouiche ${ }^{[12]}$ speculated that, despite promising in vitro results, implanted medical devices coated with silver have not been proven to be infection-resistant in the majority of studies. The conflicting results of the reports can be due to the factors such as minimal release or non-release of silver-coated surfaces and limitations dictated by potential silver toxicities. The silver toxicity is correlated to its bioavailability and determined by its solubility, oxidation state, complexation ability toward biological targets, excretion, and detoxification routes. In the literature, the probable cause of the discrepancy between the studies on the antimicrobial activity and toxicity of silver relates to the amount of silver and the way silver is given (i.e., metallic silver, ionic silver, or nanoparticle silver). Therefore, the silver form is as important as the total amount of silver for the toxicity. ${ }^{[26,27]}$
It has been reported that intravenous administration of about $0.6 \mathrm{~g}$ of silver can lead to argyria which is the only known clinical picture of chronic silver intoxication. ${ }^{[28]}$ The authors concluded that higher levels of silver, up to $0.1 \mathrm{mg} / \mathrm{L}$ (a concentration that gives a total dose over 70 years of half the human No Observed Adverse Effect Level [NOAEL]- of $10 \mathrm{~g}$ ), could then be tolerated without any risk to health. ${ }^{[29]}$ The co-sputtered silver-containing HA coatings (2.05 wt \% Ag) exhibited no osteoblast-precursor cell cytotoxicity with an antibacterial property. A number of studies have previously reported the development of a new silver ion doped nano-size calcium phosphate-based ceramic powder. ${ }^{[13,14]}$ It has been demonstrated that the powder prevents infection and does not disturb angiogenesis, which plays a key role in osseous tissue growth and, at used concentrations, it is not cytotoxic. Our microbiological results specifically proved that silver ion doped nano-size calcium phosphate-based powder-coated titanium pins reduced the bacterial colonization significantly. ${ }^{[30]}$ Free silver ions were not detected in the liquid surrounding the coated implant, since the silveradded ceramic powder is not dissolved in the liquid medium. The presence of silver ions trapped in the porous material ensures the contact killing locally over a sustained time without the risk of toxicity to host and resistance of the pathogens.

Nonetheless, there are some limitations. This is an in vitro study, and the results may not be directly related to clinical cases. Only one type of bacteria, S. epidermidis, was used in this study. Although S. epidermidis is the most common cause of infection, it is not the only cause of implant-associated infections. The detection method used for broth silver level, atomic absorption spectroscopy, is not usually considered the most sensitive method. The levels, however, may be below the detection of atomic absorption spectroscopy.

In conclusion, this in vitro study demonstrated better outcomes of silver ion doped HA coating in the prevention of the bacterial colonization than the uncoated or pure HA-coated pins. Based on these results, this technique can potentially reduce implantrelated infection.

\section{Declaration of conflicting interests}

The authors declared no conflicts of interest with respect to the authorship and/or publication of this article.

\section{Funding}

The authors received no financial support for the research and/or authorship of this article. 


\section{REFERENCES}

1. Çağlar Ö, Tokgözoğlu M, Akgün RC, Atilla B. Lowdose vancomycin-loaded cement spacer for two-stage revision of infected total hip arthroplasty. Jt Dis Relat Surg 2020;31:449-55.

2. Gristina AG, Costerton JW. Bacterial adherence and the glycocalyx and their role in musculoskeletal infection. Orthop Clin North Am 1984;15:517-35.

3. Veerachamy S, Yarlagadda T, Manivasagam G, Yarlagadda PK. Bacterial adherence and biofilm formation on medical implants: a review. Proc Inst Mech Eng H 2014;228:1083-99.

4. de Groot K, Geesink R, Klein CP, Serekian P. Plasma sprayed coatings of hydroxylapatite. J Biomed Mater Res 1987;21:1375-81.

5. Klein CP, Patka P, van der Lubbe HB, Wolke JG, de Groot K. Plasma-sprayed coatings of tetracalciumphosphate, hydroxyl-apatite, and alpha-TCP on titanium alloy: an interface study. J Biomed Mater Res 1991;25:53-65.

6. Thomas KA, Kay JF, Cook SD, Jarcho M. The effect of surface macrotexture and hydroxylapatite coating on the mechanical strengths and histologic profiles of titanium implant materials. J Biomed Mater Res 1987;21:1395-414.

7. Darouiche RO. Antimicrobial approaches for preventing infections associated with surgical implants. Clin Infect Dis 2003;36:1284-9.

8. Campoccia D, Montanaro L, Arciola CR. The significance of infection related to orthopedic devices and issues of antibiotic resistance. Biomaterials 2006;27:2331-9.

9. Li B, Webster TJ. Bacteria antibiotic resistance: New challenges and opportunities for implant-associated orthopedic infections. J Orthop Res 2018;36:22-32.

10. Alt $V$, Bechert $T$, Steinrücke $P$, Wagener $M$, Seidel $\mathrm{P}$, Dingeldein E, et al. An in vitro assessment of the antibacterial properties and cytotoxicity of nanoparticulate silver bone cement. Biomaterials 2004;25:4383-91.

11. Bosetti M, Massè A, Tobin E, Cannas M. Silver coated materials for external fixation devices: in vitro biocompatibility and genotoxicity. Biomaterials 2002;23:887-92.

12. Darouiche RO. Anti-infective efficacy of silver-coated medical prostheses. Clin Infect Dis 1999;29:1371-7.

13. Pekşen C, Koparal AS, Doğan A. Antibacterial Activity of $\mathrm{Ag}+$ ion doped calcium phosphate based ceramic power and assessment of its cytotoxicity. Proceedings of the 10th international conference of the European Ceramic Society (ECerS): June 17-21, 2007 Berlin: European Ceramic Society; 2007. p. 17-21.

14. Bostancioğlu RB, Peksen C, Genc H, Gürbüz M, Karel FB, Koparal AS, et al. Analyses of the modulatory effects of antibacterial silver doped calcium phosphate-based ceramic nano-powder on proliferation, survival, and angiogenic capacity of different mammalian cells in vitro. Biomed Mater 2015;10:045024.

15. Baldin EKK, Malfatti CF, Rodói V, Brandalise RN. Effect of Sterilization on the Properties of a Bioactive Hybrid Coating Containing Hydroxyapatite. Advances in Materials Science and Engineering 2019;2019:13.

16. Qin Z, Zhang J, Hu Y, Chi Q, Mortensen NP, Qu D, et al. Organic compounds inhibiting S. epidermidis adhesion and biofilm formation. Ultramicroscopy 2009;109:881-8.

17. Praemer A, Furner S, Rice DP. Musculoskeletal conditions in the United States. 1st ed. Illinois: American Academy of Orthopaedic Surgeons; 1992. p. 27-41.

18. Brunette DM, Tengvall $\mathrm{P}$, Textor $\mathrm{M}$, Thomsen $\mathrm{P}$. Titanium in Medicine: Material Science, Surface Science, Engineering, Biological Response and Medical Applications (Engineering Materials). Berlin: Springer-Verlag Berlin Heidelberg; 2001.

19. Pan C, Zhou Z, Yu X. Coatings as the useful drug delivery system for the prevention of implant-related infections. J Orthop Surg Res 2018;13:220.

20. Romanò CL, Scarponi S, Gallazzi E, Romanò D, Drago L. Antibacterial coating of implants in orthopaedics and trauma: a classification proposal in an evolving panorama. J Orthop Surg Res 2015;10:157.

21. Fabritius M, Al-Munajjed AA, Freytag C, Jülke H, Zehe $\mathrm{M}$, Lemarchand T, et al. Antimicrobial Silver Multilayer Coating for Prevention of Bacterial Colonization of Orthopedic Implants. Materials (Basel) 2020;13:1415.

22. Wiglusz RJ, Kedziora A, Lukowiak A, Doroszkiewicz W, Strek W. Hydroxyapatites and europium (III) doped hydroxyapatites as a carrier of silver nanoparticles and their antimicrobial activity. J Biomed Nanotechnol 2012;8:605-12.

23. Maier GS, Roth KE, Andereya S, Birnbaum K, Niedhart C, Lühmann $M$, et al. In vitro elution characteristics of gentamicin and vancomycin from synthetic bone graft substitutes. Open Orthop J 2013;7:624-9.

24. Cobb LH, McCabe EM, Priddy LB. Therapeutics and delivery vehicles for local treatment of osteomyelitis. J Orthop Res 2020;38:2091-103.

25. Percival SL, Bowler PG, Russell D. Bacterial resistance to silver in wound care. J Hosp Infect 2005;60:1-7.

26. Guo H, Zhang J, Boudreau M, Meng J, Yin JJ, Liu J, et al. Intravenous administration of silver nanoparticles causes organ toxicity through intracellular ROS-related loss of inter-endothelial junction. Part Fibre Toxicol 2016;13:21.

27. Ratte HT. Bioaccumulation and toxicity of silver compounds: A review. Environmental Toxicology and Chemistry 1999;18:89-108.

28. World Health Organization \& International Programme on Chemical Safety. Guidelines for drinking-water quality. Vol. 2, Health criteria and other supporting information. 2nd ed. Geneva: World Health Organization; 1996.

29. Atik OŞ. Is there something new and interesting in my article? Eklem Hastalik Cerrahisi 2019;30:69.

30. Chen W, Liu Y, Courtney HS, Bettenga M, Agrawal CM, Bumgardner JD, et al. In vitro anti-bacterial and biological properties of magnetron co-sputtered silver-containing hydroxyapatite coating. Biomaterials 2006;27:5512-7. 